\title{
Behavior of Ternary Mixtures of Hydrogen Bond Acceptors and Donors in Terms of Band Gap Energies
}

\author{
Alberto Mannu ${ }^{1, *(\mathbb{D}}$, Francesca Cardano ${ }^{1}\left(\mathbb{D}\right.$, Salvatore Baldino ${ }^{1}\left(\mathbb{D}\right.$ and Andrea Fin ${ }^{2}(\mathbb{C}$ \\ 1 Department of Chemistry, University of Turin, Via Pietro Giuria 7, I-10125 Turin, Italy; \\ francescacardano@gmail.com (F.C.); salvatore.baldino@unito.it (S.B.) \\ 2 Department of Drug Science and Technology, University of Turin, Via Pietro Giuria 9, I-10125 Turin, Italy; \\ andrea.fin@unito.it \\ * Correspondence: albertomannu@gmail.com
}

Citation: Mannu, A.; Cardano, F.;

Baldino, S.; Fin, A. Behavior of Ternary Mixtures of Hydrogen Bond Acceptors and Donors in Terms of Band Gap Energies. Materials 2021, 14 , 3418. https://doi.org/10.3390/ ma14123418

Academic Editors: Matteo Tiecco and Haralampos N. Miras

Received: 17 May 2021

Accepted: 18 June 2021

Published: 20 June 2021

Publisher's Note: MDPI stays neutral with regard to jurisdictional claims in published maps and institutional affiliations.

Copyright: (c) 2021 by the authors. Licensee MDPI, Basel, Switzerland. This article is an open access article distributed under the terms and conditions of the Creative Commons Attribution (CC BY) license (https:/ / creativecommons.org/licenses/by/ $4.0 /)$.

\begin{abstract}
Three ternary mixtures composed by choline chloride $(\mathrm{ChCl})$, ethylene glycol $(\mathrm{EG})$, and a second hydrogen bond donor (HBD) as ethanol (A), 2-propanol (B), and glycerol (C) were studied in terms of composition related to the band gap energy (BGE). A Design of Experiments (DoE) approach, and in particular a Simple Lattice three-components design, was employed for determining the variation of the BGE upon the composition of each system. UV-VIS analysis and subsequent Tauc plot methodology provided the data requested from the DoE, and multivariate statistical analysis revealed a drop of the BGE in correspondence to specific binary compositions for systems $\mathrm{A}$ and $\mathrm{B}$. In particular, a BGE of $3.85 \mathrm{eV}$ was registered for the mixtures $\mathrm{ChCl} / \mathrm{EtOH}$ (1:1) and $\mathrm{ChCl}$ /2-propanol (1:1), which represents one of the lowest values ever observed for these systems.
\end{abstract}

Keywords: eutectic mixtures; hydrogen bond acceptor; hydrogen bond donor; design of experiments; Tauc plot; band gap energy

\section{Introduction}

Hydrogen bond-based systems have been affirmed during the last 20 years as one of the most recurrent topics in the scientific literature [1]. In particular, the possibility to combine in a eutectic molar ratio Hydrogen Bond Acceptors (HBAs) and Hydrogen Bond Donors (HBDs) and form liquid mixtures at room temperature with increased solvent ability, which was reported for the first time by Abbott et al. in 2003 (choline chloride/urea 1:2) [2], created opportunity for many applications in several research and industrial sectors. Since the first paper of Abbot about the topic, dozens of such systems have been developed, characterized, and studied in terms of physical-chemical properties [3-5]. These systems are of particular interest when the molar ratio between HBAs and HBDs produces a drop of the melting point which produces experimental results deeper than the expected theoretical ones $[3,6]$. When this specific combination takes place, a concomitant increased solvent ability is also observed [7], and for this reason, the acronym DESs has been proposed, which stands for Deep Eutectic Solvents. Through the years, many researchers have been trigged by the possibility of engineering DESs by choosing opportune combinations of HBAs and HBDs and by finding the best molar ratio between them [6]. At the molecular level, most of the DESs can be described according to the hole theory [8] and rationalized as systems made by an intense hydrogen bond network decorated with randomly distributed holes, where the ions can move along the network by jumping from one hole to another [9]. This supramolecular behavior gives to the system peculiar properties such as an increased density, a decreased viscosity, and a low conductivity [1]. On the basis of such characteristics, DESs have found many applications as media for biomass treatment [10], metal extraction [11], solvents for Volatile Organic Compounds (VOCs) [12,13], templates for ionothermal synthesis [14-16], or non-innocent solvents in organic synthesis [17-21], as well as additives in pharmaceutical formulations [1,22,23]. 
Recently, some preliminary studies have highlighted how the deep eutectic composition in mixtures of hydrogen bond acceptors and donors is related to a depression of the band gap energy $[24,25]$ along with a drop of the structural disorder (Urbach energy) [26]. The possibility to tune such optical parameters results is of interest especially for the development of new liquid organic semiconductors.

In this context, the possibility to model the band gap energy (BGE) and monitoring its variation in ternary mixtures composed by one $\mathrm{HBA}$ (choline chloride, $\mathrm{ChCl}$ ), a first $\mathrm{HBD}$ (ethylene glycol, EG), and a second HBD (ethanol-EtOH (A), 2-propanol (B), or glycerolGLY (C)) is herein explored. In particular, a Design of Experiments (DoE) approach followed by multivariate analysis was employed to finally plot a surface representative of the variation of the BGE depending on the molar fraction ratio between the constituents of each system. According to the DoE, seven samples were prepared for each one of the three systems (A, B, C) for a total of 21 experiments, which were subjected to the graphical Tauc plot method for the determination of the BGE.

\section{Experimental Section}

\subsection{General Synthetic Procedure}

Chemicals were purchased from commercial sources and used as received. In particular, choline chloride (>98\%) and 2-propanol $(99.8 \%)$ were purchased from Merck KGaA, Darmstadt, Germany, ethanol (96\%) and glycerol (99.6\%) were purchased from VWR, and ethylene glycol $(99 \%)$ was purchased from Carlo Erba. Finally, $\mathrm{H}_{2} \mathrm{O}$ was purified with a Millipore $\mathrm{RiO}_{\mathrm{s}} 3$ Water System.

The samples were prepared following this protocol: $\mathrm{ChCl}$ was weighted in a vial, and $10 \mathrm{wt} \%$ of water was added. Thus, one or two hydrogen bond donors were added, and the resulting mixture was stirred for $2 \mathrm{~h}$ at room temperature before the analysis.

\subsection{Spectroscopic UV-VIS Analysis}

The samples were analyzed in a pure form by UV-VIS spectrophotometry. The spectra were recorded in transmittance mode in a quartz cell (path length: $1.00 \mathrm{~mm}$ ) with an Agilent Cary 60 UV-Vis Spectrophotometer.

\subsection{Statistical Analysis}

Design of Experiment (DoE): a Simple Lattice three-components design was settled up [27] Thus, for each ternary system, we prepared seven samples with the molar ratio as reported in Table 1.

Table 1. BGEs and corresponding nomenclature for the systems A-C.

\begin{tabular}{|c|c|c|c|c|}
\hline $\operatorname{HBA}(\chi)^{1}$ & $\operatorname{HBD}(\chi)$ & $\operatorname{HBD}(\chi)$ & Name & BGE $(\mathrm{eV})$ \\
\hline $\mathrm{ChCl}(1)$ & EG (0) & EtOH (0) & A1 & 5.75 \\
\hline $\mathrm{ChCl}(0)$ & EG (1) & $\mathrm{EtOH}(0)$ & $\mathrm{A} 2$ & 5.66 \\
\hline $\mathrm{ChCl}(0)$ & EG (0) & $\mathrm{EtOH}(1)$ & A3 & 5.88 \\
\hline $\mathrm{ChCl}(0.5)$ & EG (0.5) & $\mathrm{EtOH}(0)$ & A4 & 5.86 \\
\hline $\mathrm{ChCl}(0.5)$ & $\mathrm{EG}(0)$ & $\mathrm{EtOH}(0.5)$ & A5 & 3.85 \\
\hline $\mathrm{ChCl}(0)$ & EG (0.5) & $\mathrm{EtOH}(0.5)$ & A6 & 6.05 \\
\hline $\mathrm{ChCl}(0.33)$ & EG (0.33) & $\mathrm{EtOH}(0.33)$ & A7 & 5.87 \\
\hline $\mathrm{ChCl}(1)$ & EG (0) & 2-propanol (0) & B1 & 5.75 \\
\hline $\mathrm{ChCl}(0)$ & EG (1) & 2-propanol (0) & B2 & 5.66 \\
\hline $\mathrm{ChCl}(0)$ & EG (0) & 2-propanol (1) & B3 & 5.88 \\
\hline $\mathrm{ChCl}(0.5)$ & EG (0.5) & 2-propanol (0) & B4 & 5.87 \\
\hline $\mathrm{ChCl}(0.5)$ & $\mathrm{EG}(0)$ & 2-propanol (0.5) & B5 & 3.85 \\
\hline $\mathrm{ChCl}(0)$ & $\mathrm{EG}(0.5)$ & 2-propanol (0.5) & B6 & 6.05 \\
\hline $\mathrm{ChCl}(0.33)$ & EG (0.33) & 2-propanol (0.33) & B7 & 5.84 \\
\hline $\mathrm{ChCl}(1)$ & EG (0) & GLY (0) & $\mathrm{C} 1$ & 5.75 \\
\hline
\end{tabular}


Table 1. Cont.

\begin{tabular}{ccccc}
\hline HBA $(\chi)^{\mathbf{1}}$ & HBD $(\chi)$ & HBD $(\chi)$ & Name & BGE (eV) \\
\hline $\operatorname{ChCl}(0)$ & EG (1) & GLY $(0)$ & C2 & 5.66 \\
$\mathrm{ChCl}(0)$ & EG (0) & GLY (1) & C3 & 5.23 \\
$\mathrm{ChCl}(0.5)$ & EG (0.5) & GLY (0) & C4 & 5.86 \\
$\mathrm{ChCl}(0.5)$ & EG (0) & GLY (0.5) & C5 & 5.51 \\
$\mathrm{ChCl}(0)$ & EG (0.5) & GLY (0.5) & C6 & 5.17 \\
$\mathrm{ChCl}(0.33)$ & EG $(0.33)$ & GLY $(0.33)$ & C7 & 5.12 \\
\hline
\end{tabular}

${ }^{1}$ To each $\mathrm{ChCl}$ sample $10 \mathrm{wt} \%$ of water was added to make the samples measurable at UV-VIS.

Multivariate analysis, including the Analysis of the Variance (ANOVA) and the corresponding surface plots, was conducted with the Statgraphics Centurion v 18 software, Statgraphics Technologies, Inc. The Plains, Virginia.

\section{Results and Discussion}

Ternary systems A, B, and C were prepared by combining ChCl, EG, and a second HBD. The choice of the second HBD was driven by the affinity of alcohols with $\mathrm{ChCl}$ and EG; thus, EtOH, 2-propanol, and GLY were selected.

The aim of the research was to develop a tool for engineering a ternary mixture of HBAs and HBDs in terms of BGE. Thus, the first target was to model the variation of the BGE in each ternary system A, B, and C and to provide a suitable statistical instrument for describe these mixtures. In order to reach such goal, a DoE approach was used, and in particular, a Simple Lattice three-components mixture experiment was implemented [28].

Seven different molar combinations were prepared for each system, and the corresponding BGEs were determined by the known graphic UV-VIS-based Tauc plot method, following a procedure previous optimized by some of us [24].

In Table 1, the nomenclature corresponding to the systems prepared and subjected to UV-VIS analysis is reported.

In Figure 1, the UV-VIS spectra of representative binary systems A5, C5, and the thernary ones A7, C7 are reported.

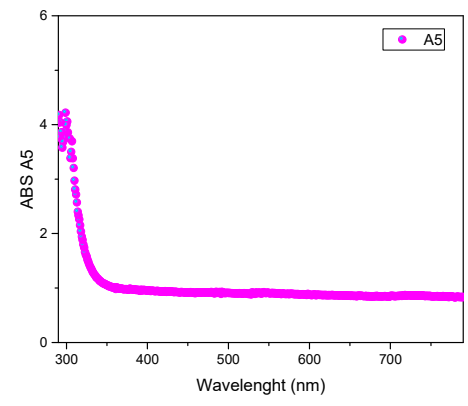

(a)

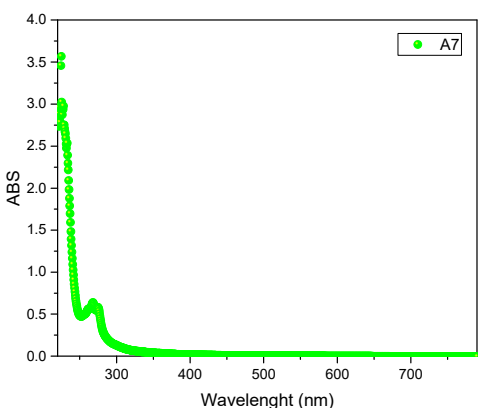

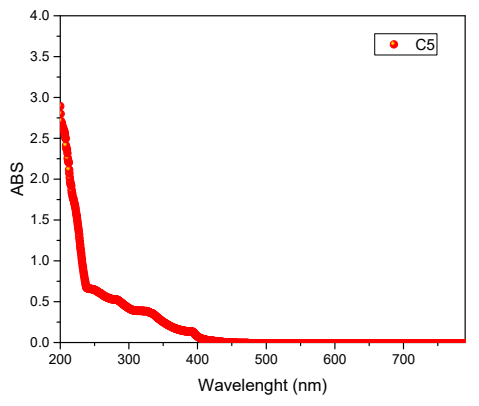

(b)

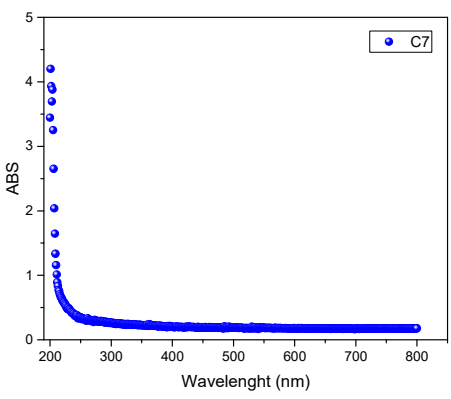

Figure 1. UV-VIS spectra of systems A5 (a), C5 (b), A7 (c), and C7 (d). 
From a visual and qualitative analysis of the UV-VIS spectra of the systems reported in Figure 1, it is possible to notice some differences. In particular, systems $\mathrm{A} 5 \mathrm{a}, \mathrm{ChCl} / \mathrm{EG}$ $1 / 1)$, and $\mathrm{C7}(\mathrm{d}, \mathrm{ChCl} / \mathrm{EG} / \mathrm{GLY} 1 / 1 / 1)$ show the same UV-VIS behavior, suggesting that the addition of glycerol does not affect in a relevant way the optical characteristics of the system. On the other side, systems $\mathrm{C} 5$ (b, $\mathrm{ChCl} / \mathrm{GLY} 1 / 1)$ and $\mathrm{A} 7$ (c, $\mathrm{ChCl} / \mathrm{EG} / \mathrm{EtOH}$ $1 / 1 / 1$ ) reveal different absorbance spectra, with $C 5$ showing multiple absorbance peaks between 200 and $400 \mathrm{~nm}$, and A7 highlighting a relevant peak at $270 \mathrm{~nm}$. Nevertheless, it is difficult to extrapolate trends and information from the analysis of the UV-VIS spectra. On the other side, the calculation of the band gap energy from the UV-VIS data can provide many information, which can be related with the structural effects of the constituents on the system.

Looking at the band gap data reported in Table 1, it is possible to highlight some trends. Each single component, measured in pure form, shows a relatively high BGE: $\mathrm{BGE}_{\mathrm{ChCl}} 5.75 \mathrm{eV}, \mathrm{BGE}_{\mathrm{EtOH}} 5.88 \mathrm{eV}, \mathrm{BGE}_{\mathrm{GLY}} 5.23 \mathrm{eV}$, and $\mathrm{BGE}_{\mathrm{EG}} 5.66 \mathrm{eV}$. As expected, when two HBDs are combined (1:1 molar ratio), no significant drop of the BGE is observed: $\mathrm{BGE}_{\mathrm{EG} / \mathrm{EtOH}} 6.05 \mathrm{eV}$ (A6), BGE $\mathrm{EG}_{\text {/2-propanol }} 6.05$ (B6), BGE $\mathrm{EG/GLY} 5.17 \mathrm{eV}$ (C6). In addition, no relevant differences were observed changing $\mathrm{EtOH}$ by 2-propanol (A6 vs. B6). As a matter of fact, the deepest reduction of the BGE was observed for the binary systems A5 and B5, which do not contain EG. This value of BGE, around $3.86 \mathrm{eV}$, falls in the range of interest for potential application as an organic liquid semiconductor. It is interesting to notice that the corresponding binary system C5, composed by ChCl and GLY, shows a BGA far away from the parent A5 and B5.

In Figure 2, the reduction of the BGE obtained by substituting EG with EtOH (A4, B4, and C4 vs. A5) is reported.

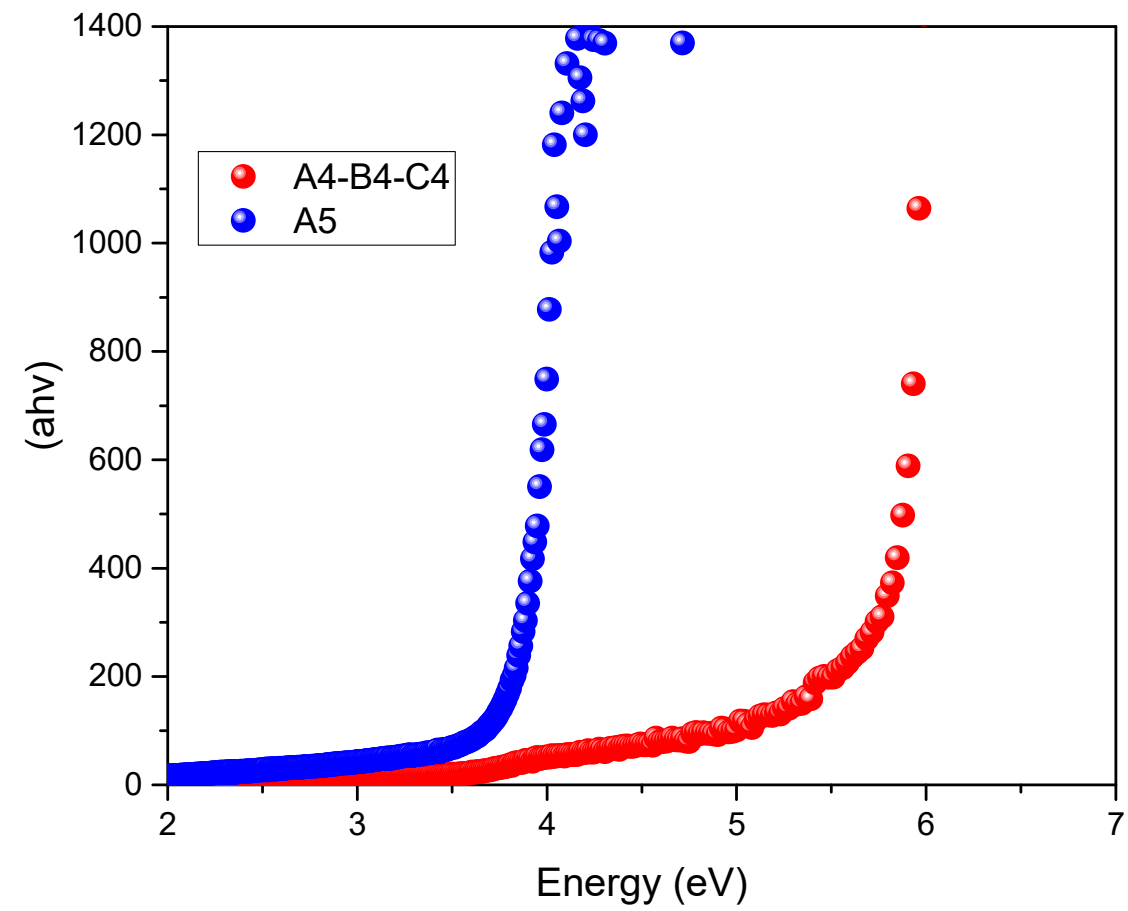

Figure 2. Tauc plots relative to the systems A4, B4, C4, ChCl/EG (1:1) and A5, ChCl/EtOH (1:1).

Each set of experiments (A, B, and C, Table 1) was processed according to the DoE procedure adopted to build a descriptive model of the variation of the BGE as a function of the molar ratio between the three constituents of the mixture. 


\section{Multivariate Analysis of Systems A, B, and C}

At first, system A composed by $\mathrm{ChCl} / \mathrm{EG} / \mathrm{EtOH}$ was analyzed with the aim to find the best statistical model that can represent the behavior of the mixture in terms of variation of the BGE. After a screening between linear, special cubic, and quadratic statistical models, the last one has been selected as the most accurate in describing the system. Full data details are reported in the Supporting Information file.

Starting from the selected quadratic model, the data obtained for the system A were subjected to the Analysis of the Variance (ANOVA), which gave the results reported in Table 2.

Table 2. ANOVA for BGE of system A.

\begin{tabular}{cccccc}
\hline Source & Sum of Squares & Df & Mean Square & F-Ratio & $p$-Value \\
\hline Quadratic model & 3.1813 & 5 & 0.63626 & 1.48 & 0.5435 \\
Total error & 0.430699 & 1 & 0.430699 & & \\
Total (corr.) & 3.612 & 6 & & & \\
\hline
\end{tabular}

ANOVA analysis shows an R-squared value that indicates that the model as fitted explains $88.0759 \%$ of the variability in BGE. The adjusted R-squared statistic, which is more suitable for comparing models with different numbers of independent variables, is $28.4553 \%$. The standard error of the estimate shows the standard deviation of the residuals to be 0.656277 . The mean absolute error (MAE) of 0.195845 is the average value of the residuals. The Durbin-Watson (DW) statistic tests the residuals to determine if there is any significant correlation based on the order in which they occur in your data file. Since the $p$-value is greater than $5.0 \%$, there is no indication of serial autocorrelation in the residuals at the $5.0 \%$ significance level.

Systems B and C were subjected to the same statistical treatment confirming the quadratic model as the best one.

For comparison purposes, the R-squared values of systems A, B, and C are reported in Table 3.

Table 3. R-squared for system A, B, and C.

\begin{tabular}{ccc}
\hline System & Statistical Model & R-Squared (\%) \\
\hline A & quadratic & 88.0759 \\
B & quadratic & 89.2872 \\
C & quadratic & 83.3460 \\
\hline
\end{tabular}

Once we determined the statistical parameters that better described the behavior of each system, it is possible to graphically represent them in the form of a responsive surface (Figure 3).

The surface responding plots reported in Figure 3 describe the variation of the systems A-C in terms of BGE. From a fist qualitative analysis, it is possible to notice that the shape of the surface that describes the behavior of the ternary mixture is very similar for systems $A$ and $B$, while it changes for system $C$. This is mainly due to the previously commented different interaction between $\mathrm{ChCl}$ and GLY (C5) with respect to $\mathrm{ChCl}$ and $\mathrm{EtOH}$ (A5) or $\mathrm{ChCl}$ and 2-propanol (B5). This experimental behavior of $\mathrm{C} 5$, combined with lower maximum values of BGE for A6 and B6 (6.04 eV), determines a flatter surface. From the combined analysis of the plots reported in Figure 3, it is possible to conclude that only systems $\mathrm{A}$ and $\mathrm{C}$ show a consistent depression of the BGE, which indeed correspond to a binary system. No one of the three systems considered performs better (in terms of lower BGE) with a ternary composition. Thus, the increment of $\mathrm{O}-\mathrm{H}$ bonds achieved with the introduction of a second HBD seems to negatively affect the eutectic nature of the mixture. 


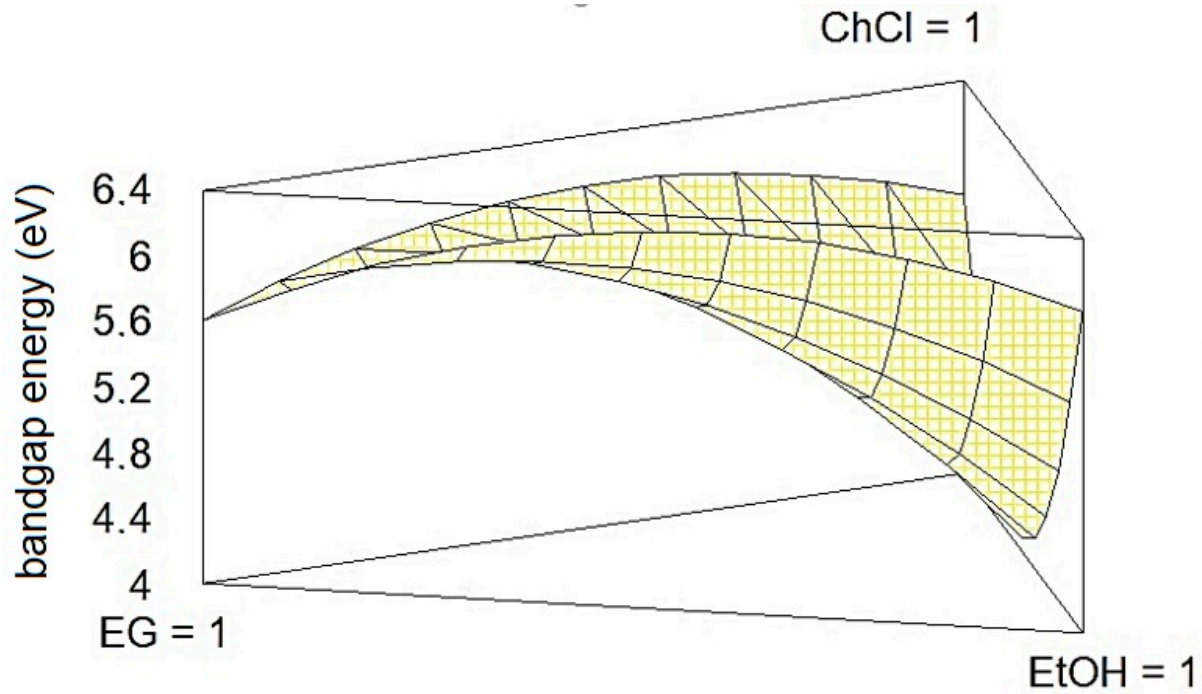

(A)

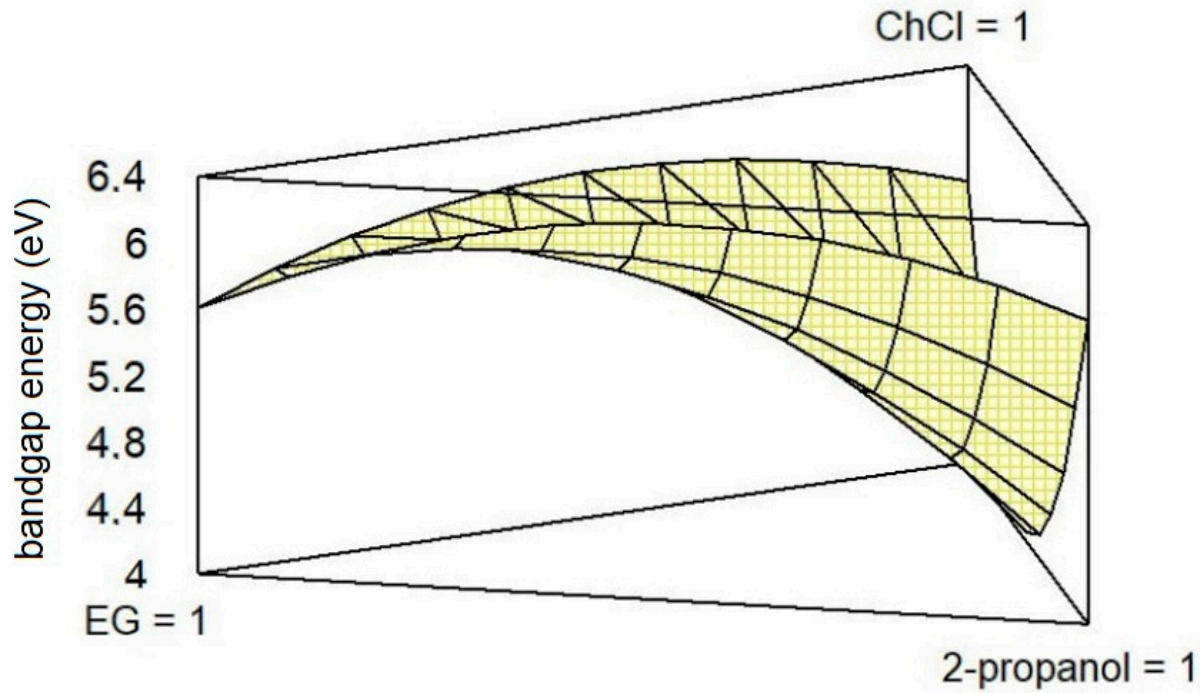

(B)

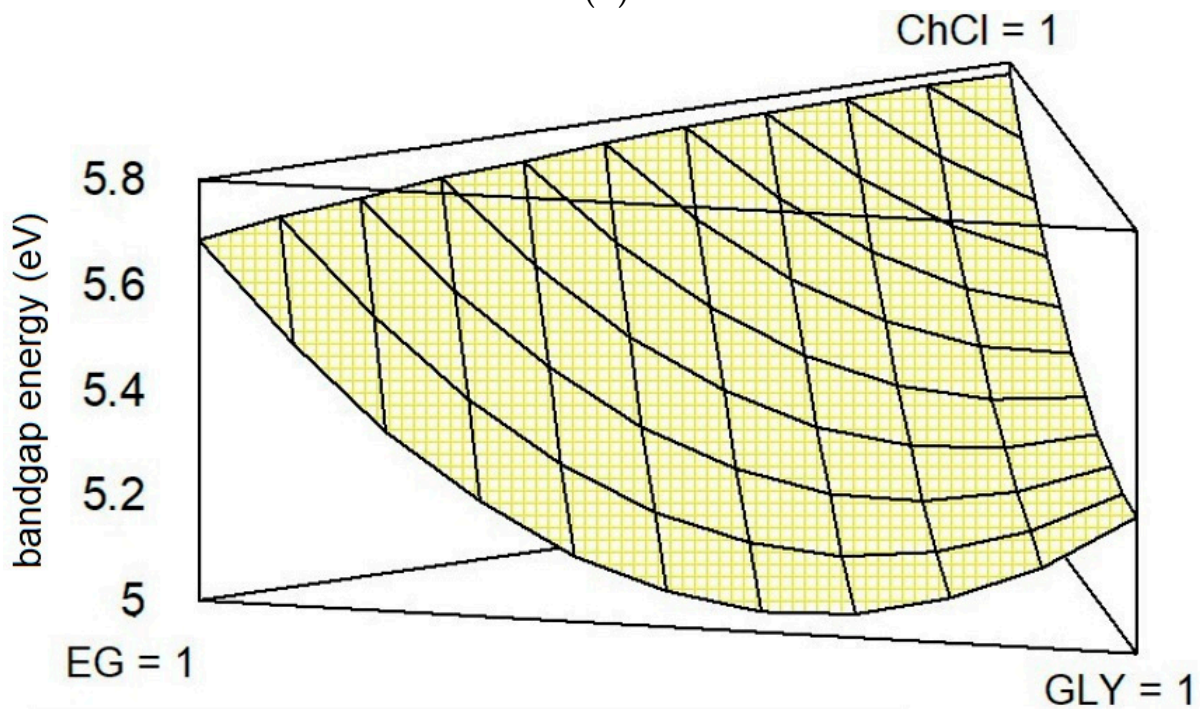

(C)

Figure 3. Estimated response surface for systems (A-(C). 
To the best of our knowledge, this study represents the first report about the variation of the BGE in ternary mixtures of HBAs and HBDs. In addition, the statistical model herein presented can be applied for optimizing other systems, even considering different parameters beyond the BGE.

\section{Conclusions}

Three ternary systems composed by $\mathrm{ChCl}$, EG, and a second HBD (EtOH, 2-propanol, GLY) were studied in terms of variation of the BGE with respect to the molar ration of the former's components. A statistical reliable model that describes the relationship between BGE and molar composition was built and described. The statistical multivariate analysis revealed, for the systems herein considered, that an excessive increasing of the $\mathrm{O}-\mathrm{H}$ bonds affects the eutectic nature of the mixture, resulting in an increasing of the BGE. In addition, the combination between UV-VIS spectroscopy, Tauc plot method (for the band gap energy determination), and the Simple Lattice DoE followed by statistical multivariate analysis provide an easy and fast tool for engineering ternary mixtures of Hydrogen Bond Donors (HBDs) and Acceptors (HBAs). In fact, the combination of techniques reported allow mapping the variation of the band gap energy versus the molar composition of the ternary system. This procedure can be used for screening purposes with the target to select the best combination between HBDs and HBAs that provides the minimum band gap energy value.

Author Contributions: Conceptualization, A.M., S.B. and A.F.; methodology, A.M. and A.F.; software, S.B.; validation, A.M.; formal analysis, F.C.; investigation, A.M.; resources, A.M.; data curation, F.C.; writing-original draft preparation, A.M.; writing-review and editing, F.C., S.B. and A.F.; supervision, A.M.; funding acquisition, A.M. All authors have read and agreed to the published version of the manuscript.

Funding: This research received no external funding.

Institutional Review Board Statement: Not applicable.

Informed Consent Statement: Not applicable.

Data Availability Statement: External data are not available.

Conflicts of Interest: The authors declare no conflict of interest.

\section{References}

1. Mannu, A.; Blangetti, M.; Baldino, S.; Prandi, C. Promising Technological and Industrial Applications of Deep Eutectic Systems. Materials 2021, 14, 2494. [CrossRef] [PubMed]

2. Abbott, A.P.; Capper, G.; Davies, D.L.; Rasheed, R.K.; Tambyrajah, V. Novel solvent properties of choline chloride/urea mixtures. Chem. Commun. 2003, 1, 70-71. [CrossRef] [PubMed]

3. Smith, E.L.; Abbott, A.P.; Ryder, K.S. Deep eutectic solvents (DESs) and their applications. Chem. Rev. 2014, 114, 11060-11082. [CrossRef]

4. Florindo, C.; Branco, L.C.; Marrucho, I.M. Quest for green-solvent design: From hydrophilic to hydrophobic (deep) eutectic solvents. ChemSusChem 2019, 12, 1549-1559. [CrossRef]

5. Liu, Y.; Friesen, J.B.; McAlpine, J.B.; Lankin, D.C.; Chen, S.-N.; Pauli, G.F.J. Natural deep eutectic solvents: Properties, applications, and perspectives. Nat. Prod. 2018, 81, 679-690. [CrossRef]

6. Martins, M.A.R.; Pinho, S.P.; Coutinho, J.A.P.J. Insights into the nature of eutectic and deep eutectic mixtures. Solut. Chem. 2019, 48, 962-982. [CrossRef]

7. Perna, F.M.; Vitale, P.; Capriati, V. Deep eutectic solvents and their applications as green solvents. Curr. Opin. Green Sustain. Chem. 2020, 21, 27-33. [CrossRef]

8. Abbott, A.P. Application of Hole Theory to the Viscosity of Ionic and Molecular Liquids. ChemPhysChem 2004, 5, 1242-1246. [CrossRef]

9. Abbott, A.P.; Capper, G.; Gray, S. Design of Improved Deep Eutectic Solvents Using Hole Theory. ChemPhysChem 2006, 7, 803-806. [CrossRef]

10. Li, X.; Row, K.H. Development of deep eutectic solvents applied in extraction and separation. J. Sep. Sci. 2016, 39, 3505-3520. [CrossRef]

11. Liu, P.; Hao, J.W.; Mo, L.P.; Zhang, Z.H. Recent advances in the application of deep eutectic solvents as sustainable media as well as catalysts in organic reactions. RSC Adv. 2015, 5, 48675-48704. [CrossRef] 
12. Moura, L.; Moufawad, T.; Ferreira, M.; Bricout, H.; Tilloy, S.; Monflier, E.; Costa Gomes, M.F.; Landy, D.; Fourmentin, S. First evidence of cyclodextrin inclusion complexes in a deep eutectic solvent. Environ. Chem. Lett. 2017, 15, 747-753. [CrossRef]

13. Di Pietro, M.E.; Colombo Dugoni, G.; Ferro, M.; Mannu, A.; Castiglione, F.; Costa Gomes, M.; Fourmentin, S.; Mele, A. Do cyclodextrins encapsulate volatiles in deep eutectic systems? ACS Sust. Chem Eng. 2019, 7, 17397-17405. [CrossRef]

14. Maschita, J.; Banerjee, T.; Savasci, G.; Haase, F.; Ochsenfeld, C.; Lotsch, B.V. Ionothermal Synthesis of Imide-Linked Covalent Organic Frameworks. Angew. Chem. Int. Ed. 2020, 59, 15750-15758. [CrossRef]

15. Wu, J.; Wang, Y.; Zhang, Y.; Meng, H.; Xu, Y.; Han, Y.; Wang, Z.; Dong, Y.; Zhang, X.J. Highly safe and ionothermal synthesis of Ti3C2 MXene with expanded interlayer spacing for enhanced lithium storage. Energy Chem. 2020, 47, 203-209. [CrossRef]

16. Zhao, X.; Duan, W.; Wang, Q.; Ji, D.; Zhao, Y.; Li, G. Microwave-assisted ionothermal synthesis of Fe-LEV molecular sieve with high iron content in low-dosage of eutectic mixture. Microporous Mesoporous Mater. 2019, 275, 253-262. [CrossRef]

17. Qin, H.; Hu, X.; Wang, J.; Cheng, H.; Chen, L.; Qi, Z. Overview of acidic deep eutectic solvents on synthesis, properties and applications. Green Energy Environ. 2020, 5, 8-21. [CrossRef]

18. Nejrotti, S.; Mannu, A.; Blangetti, M.; Baldino, S.; Fin, A.; Prandi, C. Optimization of Nazarov Cyclization of 2, 4-Dimethyl-1, 5-diphenylpenta-1, 4-dien-3-one in Deep Eutectic Solvents by a Design of Experiments Approach. Molecules 2020, $25,5726$. [CrossRef]

19. Sanyal, U.; Yuk, S.F.; Koh, K.; Lee, M.-S.; Stoerzinger, K.; Zhang, D.; Meyer, L.C.; Lopez-Ruiz, J.A.; Karkamkar, A.; Holladay, J.D.; et al. Hydrogen bonding enhances the electrochemical hydrogenation of benzaldehyde in the aqueous phase. Angew. Chem. Int. Ed. 2021, 60, 290-296. [CrossRef]

20. Hooshmand, S.E.; Afshari, R.; Ramón, D.J.; Varma, R.S. Deep eutectic solvents: Cutting-edge applications in cross-coupling reactions. Green Chem. 2020, 22, 3668-3692. [CrossRef]

21. Cavallo, M.; Arnodo, D.; Mannu, A.; Blangetti, M.; Prandi, C.; Baratta, W.; Baldino, S. Deep eutectic solvents as H2-sources for Ru (II)-catalyzed transfer hydrogenation of carbonyl compounds under mild conditions. Tetrahedron 2021, 83, 131997. [CrossRef]

22. Jablonský, M.; Škulcová, A.; Šima, J. Use of deep eutectic solvents in polymer chemistry-A review. Molecules 2019, 24, 3978. [CrossRef] [PubMed]

23. Duarte, A.R.C.; Ferreira, A.S.D.; Barreiros, S.; Cabrita, E.; Reis, R.L.; Paiva, A. A comparison between pure active pharmaceutical ingredients and therapeutic deep eutectic solvents: Solubility and permeability studies. Eur. J. Pharm. Biopharm. 2017, 114, 296-304. [CrossRef] [PubMed]

24. Mannu, A.; Ferro, M.; Colombo Dugoni, G.; Di Pietro, M.E.; Garroni, S.; Mele, A.J. From deep eutectic solvents to deep band gap systems. Mol. Liq. 2020, 301, 112441. [CrossRef]

25. Mannu, A.; Di Pietro, M.E.; Mele, A. Band-Gap energies of choline chloride and triphenylmethylphosphoniumbromide-based systems. Molecules 2020, 25, 1495. [CrossRef] [PubMed]

26. Mannu, A.; Cardano, F.; Fin, A.; Baldino, S.; Prandi, C.J. Choline chloride-based ternary deep band gap systems. Mol. Liq. 2021, 330, 115717. [CrossRef]

27. Lambrakis, D.P. Experiments with mixtures: A generalization of the simplex-lattice design. J. R. Stat. Soc. Ser. B Methodol. 1968, 30, 123-136. [CrossRef]

28. Fang, K.-T.; Liu, M.-Q.; Qin, H.; Zhou, Y.-D. Theory and Application of Uniform Experimental Designs; Springer: Berlin/Heidelberg, Germany, 2018; ISBN 978-981-13-2041-5. 